\title{
Chornic Back Pain Secondary to Brucella Spondylitis
}

Dr. Mohamad Al Farouh ${ }^{1 *}$, Dr. Sulaiman Madad ${ }^{* *}$

${ }^{1}$ Internal Medicine - Primary Health Care Corporation (PHCC), DOHA, Qata

${ }^{2}$ Ophthalmology Department - Primary Health Care Corporation (PHCC), DOHA, Qatar

DOI: $10.36347 /$ sjams.2020.v08i09.004

| Received: 01.09.2020 | Accepted: 07.09.2020 | Published: 09.09.2020

*Corresponding author: Dr. Sulaiman Madad

\section{Abstract}

Common zoonosis and the bacterial genus Brucella it causes a systemic, infectious disease called Brucellosis it is a big health problem in many places such as Latin America the Mediterranean sea region, and Middle East. It may involve tissues and multiple organs. Involvement of Osteoarticular is a complication of brucellosis most frequent, in which is difficult since in a clinical presentation the diagnosis of brucellar spondylitis. In this article we study a case of spondylitis cussed by a brucella in a 24-year old female.

Keywords: Chornic Back Pain Brucella.

Copyright @ 2020: This is an open-access article distributed under the terms of the Creative Commons Attribution license which permits unrestricted use, distribution, and reproduction in any medium for non-commercial use (NonCommercial, or CC-BY-NC) provided the original author and source are credited.

\section{INTRODUCTION}

The consumption of products or direct contact with infected animals it causes intracellular facultative bacteria of the genus Brucella. Brucellosis with a systemic infection.

Worldwide about half a million cases are reported every year; these numbers underestimate the incidence of human disease.

Most severe complications of Brucellosis affects in human body various organs, (the reticuloendothelial, musculoskeletal) system. Osteoarticular manifestations, it is difficult to diagnose because the non-specific clinical symptoms. The disease is a major health problem in the Latin America the Mediterranean Sea region, and Middle East.

First isolated of Brucella melitensis in 1886, by David Bruce and known as Malta fever

In 1897 cause of contagious abortion in cattle, Bacillus abortus was identified by Bernhard Bang

In 1932, from the human blood culture $B$.

melitensis was isolated

In 1944 from an aborted fetus, B. abortus was isolated

Brucellar spondylitis is, the most complications of brucellosis described 1932 by Vinke and Kulowski. We present a case of brucellar spondylitis as the cause of non-specific back pain, young female and review the relevant literature

\section{Case Report}

24 years old female patient, single, not known to have any previous medical illness. used to work in cattle farm in Syria for 4 years, presented to WIC at our health center with a complaint of moderate back pain radiating to the right thigh, which had gradually developed over one month prior to the visit.

This pain increased by heavy work and relieve by pain killer. She has a history of intermittent fever over period of two months, which was treated with paracetamol.

Patient seeks medical attention several times and was diagnosed to have muscular pain and given analgesia for that but without improvement.

Patient denies history of trauma, no history of loss of weight, no history of night sweating. No recent history of overseas travels, no evidence of specific family history. As per patient statement they bread sheep and goats and make unpasteurized cheese.

\author{
Physical examination \\ Patient able to bear weight \\ Pain is radiated to right thigh \\ No midline tenderness or deformity \\ intact sensation \\ Power \\ RT leg $5 / 5$ \\ LT leg $5 / 5$ \\ Leg Rising Test negative for pain
}


Normal range of motion

No drop foot

No stool or urine incontinence

The patient was referred to hospital as a case of suspected brucellosis, investigation done and diagnosed to have brucellosis.

Infection Internal Medicine department was consulted, A combined therapy of Streptomycin inj. For 15 days plus doxycycline and rifampin for 45 days orally. In follow-up appointment patient reported improvement of symptoms and back pain.

\section{Radiology Report for Lumber Spine}

\section{$X$-ray lumbar spine AP and lateral views}

- Straightening of lumber spine, denoting muscle spasm.

- $\quad$ mild narrowing at 11-12,12-13,15-s1 IV disc spaces.

- $\quad$ end plate irregularity noted in visualized vertebrae, early degenerative changes.

- No evidence of vertebral displacement

- subtle scoliotic deformity in lumbar spine.

- Both sacro-iliac joints appear intact.

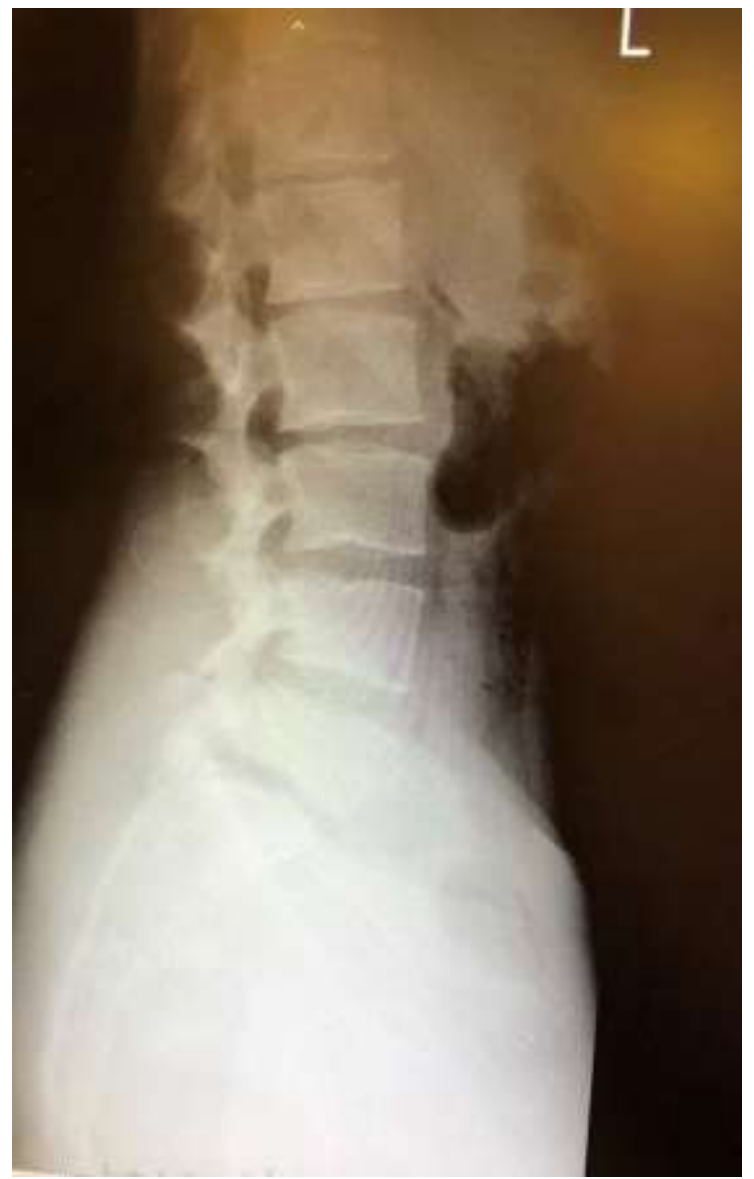

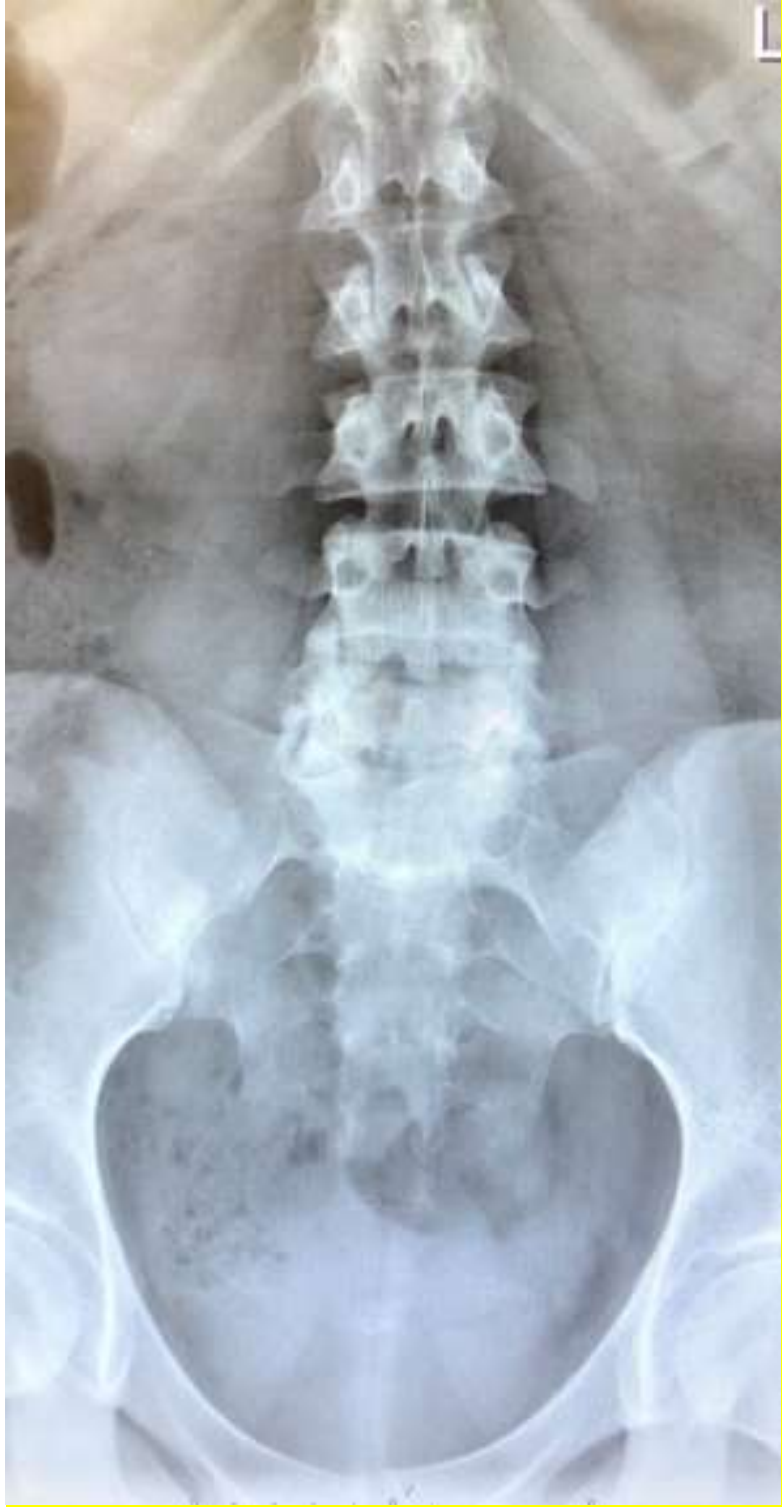

\section{DISCUSSION}

The cause of Human brucellosis is small Gram negative, aerobic coccobacilli of the genus brucella it is consider zoonotic infection and it is transmitted commonly through the ingestion of unpasteurized milk products such as cheese or raw liver, and sometimes contact with infected animals. Species that cause human brucellosis are Brucella melitensis, (B. abortus, $B$. suis and B. canis,)

After become inside human body and being taken up by local tissue lymphocytes, the Brucellae is transferred from regional lymph nodes to circulation and are subsequently seeded throughout the body, with tropism for the reticuloendothelial system. Nonspecific Symptoms are fever, headache, back pain, myalgias, and fatigue. 
It is difficult to distinguish the cause of infectious spondylitis disease by MRI (nonspecific symptoms) for brucella, the history of direct contact with the infected animals or consumption of their production it is important for early diagnosis and treatment in the suspicious patient.

The Brucellosis can affect various body organs, but the spondylitis is most frequent and significant complication of the brucellosis and reported incidence varies from $2-60 \%$ The Lumbar vertebrae are most frequently involved regions in brucellar spondylitis, followed by the cervical and thoracic segments.

The definite diagnosis of brucellosis is established by the clinical manifestation and isolation of the Brucella species from the bone marrow or blood cultures, but it is very difficult for patients who have chronic brucellosis or local complications. If there is absence of bacteriologic confirmation, a positive serology for brucella standard tube agglutinin testing (titer over 1: 160), rise in the brucella-antibody titer in interval of 2 weeks (4 FOLD RISE), is considered definitive. However, there is limitation that the sensitivity drops in early stage of disease, for this reason repeated the antibody tests is important. Another test is (ELISA) the indirect enzyme linked immune sorbent assay, It is used cytoplasmic proteins as antigens and measures immunoglobulins class G,A, and $\mathrm{M}$, which allows for the better interpretation of clinical situation and overcomes some of shortcomings of the the serum agglutination tests, the comparison with serum agglutination test yields higher specificity and sensitivity.

Development of the PCR (specific polymerase chain reaction) is the recent advancement, the PCR is fast, it can be performed on any body tissue, and can yield positive results as soon as 10 days after inoculation. Although both PCR and ELISA offer new possibilities in future for the diagnosing brucellosis, standardization of extraction methods and set up is lacking, and the better understanding of the clinical significance of the results is still needed.

The diagnostic value is little for routine laboratory in most studies, the diagnosis of brucellar spondylitis by ESR and Hemogram isn't useful.

However, in the most of case report there is increased of ESR has been observed. ESR can consider a measure for therapy response.

Various degrees of bone involvement can see by $\mathrm{x}$-ray like narrowing of the intervertebral space, gross destruction, sclerosis (patchy) of vertebral end plateau and displacement of vertebral axis. As the earliest appearances of the destructive changes visible on x-ray.
It starts approximately after 3 months of symptoms, the MRI can be considered since it is more sensitive to demonstrate early bone infection.

For patients who live in endemic areas, it is changeable to differentiate between tuberculous and brucella infections of the spine. And the reason is that Both are caused by intracellular pathogens which are difficult to isolate or identify in a short period.

Clinical finding, routine laboratory and radiological findings are usually helpful to differentiate between spinal brucellosis and vertebral tuberculosis.

\section{For example}

- In tuberculous spondylitis. Leukocyte count and ESR are relatively higher than brucellar spondylitis.

- MRI can show either unifocal or multifocal lesion in brucellar spondylitis.

- Brucella usually affects lower lumbar spine, and has intact vertebral architecture and diffuse vertebral osteomyelitis, minimal paraspinal soft tissue involvement, disc space involvement.

- Absence of gibbus deformity is suggestive features of brucellar spondylitis over other pyogenic spondylitis and tuberculous spondylitis.

- Gibbus deformity, paraspinal abscess, severe vertebra body collapse and single vertebra or disc, predilection for the midthoracic region are suggesting tuberculous spondylitis.

- Tuberculous spondylitis is affecting younger patients commonly.

There is no standard protocol to treat brucella but a various combination of antibiotics maybe considered. Streptomycin, doxycycline and rifampin (SDR) combination therapy is very effective and it can reduce failure and relapse rate.

Since brucella and tuberculosis are endemic diseases, it is very important to consider the differential diagnosis for both of them; detailed history, physical exam, MRI, and serum test should be considered for early diagnosis and treatments.

\section{REFERENCES}

1. Lee HJ, Hur JW, Lee JW, Lee SR. Brucellar spondylitis. Journal of Korean Neurosurgical Society. 2008 Oct;44(4):277.

2. Cobbaert K, Pieters A, Devinck MI, Devos M, Goethals I, Mielants H. Brucellar spondylodiscitis: case report. Acta Clinica Belgica. 2007 Oct 1;62(5):304-7.

3. Yilmaz MH, Mete B, Kantarci F, Ozaras R, Ozer H, Mert A, Mihmanli I, Ozturk R, Kanberoglu K. Tuberculous, brucellar and pyogenic spondylitis: 
comparison of magnetic resonance imaging findings and assessment of its value. Southern medical journal. 2007 Jun 1;100(6):613-5.

4. Aydin G, Tosun A, Keles I, Ayaşlioglu E, Tosun O, Orkun S. Brucellar spondylodiscitis: a case report. International journal of clinical practice. 2006 Nov;60(11):1502-5.

5. Ugarriza LF, Porras LF, Lorenzana LM, Rodríguez-Sánchez JA, García-Yagüe LM, Cabezudo JM. Brucellar spinal epidural abscesses. Analysis of eleven cases. British journal of neurosurgery. 2005 Jan 1;19(3):235-40.

6. Lim HS, Song YG, Yoo HS, Park MY, Kim JW. Brucellosis: An Overview. Korean Journal of Epidemiology. 2005 Jun 1;27(1):26-36.
7. Yilmaz E, Parlak M, Akalin H, Heper Y, Ozakin C, Mistik R, Oral B, Helvaci S, Töre O. Brucellar spondylitis: review of 25 cases. JCR: Journal of Clinical Rheumatology. 2004 Dec 1;10(6):300-7.

8. Namiduru M, Karaoglan I, Gursoy S, Bayazit N, Sirikci A. Brucellosis of the spine: evaluation of the clinical, laboratory, and radiological findings of 14 patients. Rheumatology international. 2004 May $1 ; 24(3): 125-9$.

9. Jameson JL. Harrison's principles of internal medicine. McGraw-Hill Education,; 2018.

10. Solera J, Lozano E, Martínez-Alfaro E, Espinosa A, Castillejos ML, Abad L. Brucellar spondylitis: review of 35 cases and literature survey. Clinical infectious diseases. 1999 Dec 1;29(6):1440-9. 